\title{
The Response of Lipolytic Activity in Adipose Tissue to Saturated
} Fat

\author{
${ }^{1,}$ Rasha Eldeeb, ${ }^{2,}$ Nisha Shantakumari, ${ }^{3,}$ M.H. Gamal-Eldin, ${ }^{4}$ Effat A. \\ Khowailed, ${ }^{5}$ Mona M. Fathy \\ ${ }^{1,2}$ Department of Physiology, Gulf Medical University, Ajman, UAE \\ ${ }^{3,4}$, Department of Physiology, ${ }^{5}$ Department of Chemical and Clinical Pathology, College of Medicine, Cairo \\ University (Kasr Eleinin University), Cairo, Egypt
}

\begin{abstract}
:
Introduction: Obesity has become a major problem in the modern world; it is affected genetically and by lifestyle and dietary habits as consuming fast food meals enriched with high saturated fat (SF). Since obesity is associated with multi co-morbidities like dyslipidemia, hypertension, and metabolic syndrome, this work studied the effect of diet rich in saturated fat on body weight, blood pressure, lipid profile, glycemic state and lipolytic activity of adipose tissue in male rats.
\end{abstract}

Materials and Methods: Twenty male rats of an average body weight $192.4 \mathrm{~g}$ were divided equally into two groups, control group (Cgp) fed commercial rat chow and experimental group (SFgp) fed 10\% saturated fat to induce obesity. After 3 months the body weight, blood pressure, fasting blood glucose, insulin level, and lipid profile of both groups were measured and the lipolytic activity of adipose tissue was assessed.

Results: Rats fed saturated fat for 3 months showed significant increase in body weight, systolic blood pressure, $T G$, Cholesterol, LDL, fasting blood glucose and insulin levels with a significant decline in HDL.

Lipolytic activity of SC tissue in the presence of adrenaline decreased significantly while in the presence of insulin it increased significantly. It showed a significant increase in the presence of adrenaline and insulin in visceral adipose tissue. A p value less than 0.05 was considered statistically significant.

Conclusion: Consumption of diet rich in saturated fat in male rats induced obesity that is associated with hypertension, dyslipidemia, hyperglycemia and insulin resistance. The adipose tissue of obese male rats showed a significant decrease in lipolytic activity of SC with a significant rise in the corresponding value in visceral adipose tissue.

Key Words: adipose tissue, hypertension, lipolytic activity, obesity, saturated fat.

\section{Introduction:}

Adipose tissue serves as the main fuel and energy supply for the whole body and its metabolic activity is the main contributor to the development of obesity, followed by or concomitant with insulin resistance and cardiovascular diseases [1]. The fatty acid profile of the adipocytes is determined by the composition of dietary fats[2]. Although it is well documented that the consumption of high-fat diets can induce obesity, the effect of the type of dietary fatty acid on lipid accumulation has not been elucidated[3]. Obesity is often associated with metabolic syndrome which includes insulin resistance, dyslipidemia and hypertension [4].Regional variations in adipose tissue function seem to have an additional bearing on insulin resistance. Visceral fat accumulation has a stronger association with insulin resistance than subcutaneous fat accumulation. This has in part been attributed to higher lipolytic activity in visceral than subcutaneous adipose tissue[5]. There is much evidence showing that

the function of adipose tissue is disturbed in insulin-resistant states. The ability of insulin to suppress fatty acid release from adipose tissue is impaired in obesity[6]. Intra-abdominal fat depots, although relatively small in comparison with subcutaneous fat depots, play an important role in fat buffering. The rate of lipolysis from intra-abdominal adipocytes, when measured in vitro, tends to be high[1,7].This study investigated the effect of consuming diet rich in saturated fat on the body weight, systolic blood pressure, lipid profile, glycemic state and the lipolytic activity of adipose tissue in male rats. 


\section{Materials And Methods}

The Experimental Research Committee of the Physiology Department in College of Medicine Cairo University approved all procedures. Male rats were supplied by the Animal Care Facility.

\subsection{Animals and diet preparation}

Rats of $192.4 \mathrm{~g}$ average body weight (BW) were divided into two groups of 10 rats each. The control group (Cgp) was fed commercial rat chow consisting of (w/w) Crude protein $22 \%$, Crude fat $4 \%$, Crude carbohydrate $38 \%$, Crude fibers $5 \%$, ash $8 \%$ and added minerals $3 \%$ for 3 months. The experimental group (SFgp) was fed commercial rat chow for 3 months with $10 \%$ saturated fat of animal source (sheep tail fat, Leyah) added. Food was given fresh daily; rats ate a varying amount of 15-30 grams/day and had free access to water. All groups were maintained in a room at $23^{\circ} \mathrm{C}$ with light on from 07:00 till 18:00. After 3 months the body weight, blood pressure, fasting blood glucose and insulin, serum triglyceride (TG), high density lipoprotein (HDL), low density lipoprotein (LDL) and total cholesterol levels were measured, Lipolytic activity as well as the antilipolytic activity of insulin for both visceral and subcutaneous adipose tissue were measured.

\subsection{Measurement of systolic blood pressure}

Systolic blood pressure in rats was measured by Harvard rat tail blood pressure monitor system.

\subsection{Biochemical tests}

All samples were taken from overnight unfed rats. Blood glucose was measured by glucose oxidase method (kit510-A, Sigma)[10], and Insulin level assessed by ELISA Kit (DRG Company). Serum triglycerides were measured by lipoprotein lipase technique (Colorimetric triglyceride kits DIALAB Co.)[1]. Total serum cholesterol (esterified and free forms) was measured by Colorimetric Cholesterol kit (352-20, Sigma)[11] and HDL-C by Colorimetric method (Stanbio kit No. 0599)[11]. LDL-C serum level was calculated using the following equation:[12,13]

LDL-C $=$ TC $-($ HDL-C + TG)

\section{5}

\subsection{Measurement of Lipolytic activity of adipose tissue in vitro}

Rats were killed by decapitation; the study was performed on subcutaneous adipose tissue and visceral (omental) adipose tissue. One gram samples taken from each group were immediately transported to the laboratory in Ringer's solution at room temperature and digested by Rodbell methods (Rodbell , 1964 and Rodbell et al.,1971) [8,9]. The suspension of cells was centrifuged for one minute at $4000 \mathrm{rpm}$. The fat cells floated to the surface and the stromal-vascular cells were sedimented. $50 \mu \mathrm{l}$ of adrenaline $(1 \mathrm{mg} / \mathrm{ml})$ was added to $0.5 \mathrm{ml}$ supernatant and incubated for 30 minute at $37^{\circ} \mathrm{C}$, another $0.5 \mathrm{ml}$ supernatant was mixed with $50 \mu \mathrm{l}$ of adrenaline $(1 \mathrm{mg} / \mathrm{ml})$ and incubated for 30 minute at $37^{\circ} \mathrm{C}$ followed by adding $50 \mu \mathrm{l}$ of act rapid insulin $(100 \mathrm{U} / \mathrm{ml})$ to it and incubated for another 30 minutes.Lipolytic activity was determined by measuring free glycerol released from fat cells of each set (by Colorimetric kits DIALAB Co. [1].

\subsection{Drugs used}

Bovine serum albumin (BSA; A 6003, essentially fatty acid-free, Sigma), collagenase IV (Sigma Co.), adrenalin (Sigma), Insulin (EIL LILLY Co.) and a buffer containing the following (in mM): $137 \mathrm{NaCl}, 5 \mathrm{KCl}$, 4.2 $\mathrm{NaHCO}_{3}, 1.3 \mathrm{CaCl}_{2}, 0.5 \mathrm{MgCl}_{2}, 0.5 \mathrm{KH}_{2} \mathrm{PO}_{4}, 0.5 \mathrm{MgSO}_{4}, 20 \mathrm{HEPES}$ (pH 7.4), and 1\% BSA. The buffer mentioned above was supplemented with $5 \mathrm{mM}$ glucose.

\subsection{Statistical analysis}

Results are expressed as mean values with their standard deviation. The Student's t test was used to compare the two groups. Significance was set at $\mathrm{P}<0.05$ level.

\section{Results: (Table 1)}

3.1 Changes in Body Weight: Rats in Cgp weighed $192.4 \pm 8.11$ g. In SFgp BW increased to $298.8 \pm 84.43 \mathrm{~g}$ showing a significant increase by $55.3 \%$ compared to Cgp.

3.2 Changes in Systolic Blood pressure: Systolic BP in Cgp was $121 \pm 6.51 \mathrm{~mm} \mathrm{Hg}$. In SFgp it increased to $140.2 \pm 13.163 \mathrm{~mm} \mathrm{Hg}$ showing a significant increase of $15.86 \%$ relative to Cgp.

3.3 Changes in Lipid Profile: Triglyceride level in Cgp was $54.1 \pm 8.87 \mathrm{mg} / \mathrm{dl}$, it increased to $67.1 \pm 15.32$ $\mathrm{mg} / \mathrm{dl}$ in SFgp, showing a significant increase by $24 \%$ compared to Cgp. Cholesterol level in Cgp was $84.78 \pm$ $4.76 \mathrm{mg} / \mathrm{dl}$. It showed a significant increase in SFgp by 7.92\%.HDL and LDL levels in Cgp were $30.1 \pm$ 
$1.911 \mathrm{mg} / \mathrm{dl}$ and $43.65 \pm 2.80 \mathrm{mg} / \mathrm{dl}$ respectively. In SFgp HDL level decreased to $26.19 \pm 2.578 \mathrm{mg} / \mathrm{dl}$ showing a significant decrease by $12.9 \%$ compared to Cgp, while LDL level in SFgp increased to $52.2 \pm 5.754 \mathrm{mg} / \mathrm{dl}$ showing a significant increase by $19.58 \%$ to compared to Cgp.

3.4 Fasting Blood Glucose and Insulin levels: Blood glucose level in Cgp $76.8 \pm 6.39 \mathrm{mg} / \mathrm{dl}$ it increased to $92.6 \pm 13.59 \mathrm{mg} / \mathrm{dl}$ in SFgp showing a significant increased by $20.5 \%$ in SFgp compared to Cgp . It runs parallel to results observed in insulin level as insulin as it was $0.157 \pm 0.087 \mu / 1$ in Cgp and it increased to $0.199 \pm$ $0.0823 \mu \mathrm{g} / \mathrm{l}$ in SFgp showing a significant increase by $26.25 \%$ in SFgp compared to C gp.

3.5 Lipolytic activity of subcutaneous (SC) adipose tissue: In the presence of adrenaline, lipolytic activity of SC tissue significantly decreased by $15 \%$ in SFgp compared to Cgp. It was $176.6 \pm 43.36 \mathrm{mg} / \mathrm{dl}$ in Cgp versus $150.32 \pm 14.88 \mathrm{mg} / \mathrm{dl}$ in SFgp. In presence of insulin it significantly increased by $33.33 \%$ in SFgp compared to Cgp. It was $11.05 \pm 4.42 \mathrm{mg} / \mathrm{dl}$ in Cgp versus $14.40 \pm 3.89 \mathrm{mg} / \mathrm{dl}$ in SFgp. In the presence of insulin, it increased significantly by $25.84 \%$ in SFgp compared to Cgp. It was $27.03 \pm 6.65 \mathrm{mg} / \mathrm{dl}$ in Cgp versus $34.01 \pm 7.39 \mathrm{mg} / \mathrm{dl}$ in SFgp. Moreover, the lipolytic activity of visceral adipose tissue in the presence of adrenalin was significantly higher than lipolytic activity of SC adipose tissue; it was $210.03 \pm 54.125 \mathrm{mg} / \mathrm{dl}$ in visceral adipose tissue in Cgp versus $176.6 \pm 43.36 \mathrm{mg} / \mathrm{dl}$ in SC adipose tissue in Cgp, and in SFgp it was $247.8 \pm 89.7$ $\mathrm{mg} / \mathrm{dl}$ in visceral adipose tissue versus $150.32 \pm 14.88 \mathrm{mg} / \mathrm{dl}$ in SC adipose tissue. In the presence of insulin the lipolytic activity of visceral adipose tissue was significantly higher than SC adipose tissue; in Cgp it was $27.03 \pm$ $6.65 \mathrm{mg} / \mathrm{dl}$ versus $11.05 \pm 4.42 \mathrm{mg} / \mathrm{dl}$ in SC tissue. In SFgp it was $34.01 \pm 7.39 \mathrm{mg} / \mathrm{dl}$ in visceral adipose tissue versus $14.40 \pm 3.89 \mathrm{mg} / \mathrm{dl}$ in $\mathrm{SC}$ adipose tissue.

3.6 Lipolytic activity of visceral adipose tissue: Contrary to its activity in SC, lipolytic activity of visceral adipose tissue in presence of adrenaline significantly increased by $18 \%$ in SFgp compared to Cgp. It was 210.03 $\pm 45.125 \mathrm{mg} / \mathrm{dl}$ in Cgp versus $247.8 \pm 89.7 \mathrm{mg} / \mathrm{dl}$ in SFgp.

Table 1. Effects of Diet Rich in Saturated Fat on Male Rats

\begin{tabular}{|c|c|c|c|c|c|c|}
\hline \multirow[t]{2}{*}{ Parameters } & \multicolumn{2}{|c|}{ Control group } & \multicolumn{2}{|c|}{ Experimental group } & \multirow{2}{*}{$\begin{array}{l}\% \\
\text { change }\end{array}$} & \multirow[t]{2}{*}{$\mathrm{p}$} \\
\hline & Mean & SD & Mean & SD & & \\
\hline Body weight (BW) (g) & 192 & 8.11 & 298.8 & 84.43 & 55.3 & $<0.05$ \\
\hline $\mathrm{SBP}(\mathrm{mmHg})$ & 121 & 6.51 & 140.2 & 13.163 & 15.86 & $<0.05$ \\
\hline TG & 54.1 & 8.87 & 67.1 & 15.32 & 24 & $<0.05$ \\
\hline cholesterol & 84.78 & 7.46 & 91.5 & 8.26 & 7.92 & $<0.05$ \\
\hline HDL & 30.1 & 1.91 & 26.19 & 2.25 & -12.9 & $<0.05$ \\
\hline LDL & 43.65 & 2.80 & 52.2 & 5.75 & 19.58 & $<0.05$ \\
\hline Glucose $(\mathrm{mg} / \mathrm{dl})$ & 76.8 & 6.39 & 92.6 & 13.59 & 20.5 & $<0.05$ \\
\hline $\operatorname{Insulin}(\mu \mathrm{g} / \mathrm{l})$ & 0.16 & 0.09 & 0.20 & 0.08 & 26.25 & $<0.05$ \\
\hline Sc-adrenalin & 176.66 & 43.36 & 150.32 & 14.88 & -15 & $<0.05$ \\
\hline Visceral-adrenalin & 210.03 & 54.13 & 247.84 & 89.70 & 18 & $<0.05$ \\
\hline Sc-insulin & 11.06 & 4.42 & 14.41 & 3.89 & 30.33 & $<0.05$ \\
\hline Visceral-insulin & 27.03 & 6.56 & 34.02 & 7.39 & 25.84 & $<0.05$ \\
\hline
\end{tabular}

SBP- Systolic Blood pressure $\quad$ SC-Subcutaneous

\section{Discussion}

Many prospective studies showed that excess body fat often correlates with increased mortality, diabetes, hyperlipidemia, hypertension, and atherosclerosis [5]. Since obesity is not a homogeneous condition, the lipolytic activity of regional adipose tissue becomes important when assessing the relationship of obesity to disturbances in glucose and lipid metabolism [4, 5].In this study consumption of diet enriched with saturated fat (SF) significantly increased BW of rats by $55.3 \%$, in accordance with the findings of Alsaifa et al, who found

that animals supplemented with high fat diets showed a significant increase in body and visceral fat weights compared to rats fed low fat diets. As dietary fat is very readily absorbed and converted to body fat, it is easy to consume large amounts of fat calories before satiation occurs[12]. Duplus et al. observed that fatty acids (FAs) are inducers of the adipocyte lipid-binding protein $(\mathrm{aP} 2)$ gene transcription in pre-adipose cells, stating that FAs are potent regulators of adipogenesis. FAs induce the expansion of white adipose tissue (WAT) mass. It is possible that a common response element(s) to a FA-responsive master transcription factor is present in the promoter regions of all these genes[13].In addition, there was a significant rise in systolic blood pressure by $15.8 \%$, matching Valensi, who stated that enriched diet with SF in male rats induced a significant increase in BW and blood pressure due to sympathetic activation, enhanced sensitivity of small mesenteric arteries to 
noradrenaline and impairment of endothelium function. Impairment of insulin sensitivity in these rats together with a compensatory increase in serum insulin contributes to sympathetic activation and blood pressure increase[14]. Hypertension is also related to obesity-associated lipid metabolic disorders that enhance deposition of lipids on arterial walls [15], increase $\mathrm{Ca}_{2}{ }^{+}$channel numbers or alter channel regulation, leading to increased trans-membrane $\mathrm{Ca}_{2}{ }^{+}$flux 16 and increase VSMC levels of long-chain FAs, thus limiting or slowing the transitions of membrane channels from opened to closed state[14,17].Examination of lipid profile showed a significant increase of TG, cholesterol and LDL levels by $24 \%, 7.92 \%$ and $19.58 \%$ respectively. HDL showed a significant decrease by $12.9 \%$ which correlated with Ajayi et al[16], who found a significant decrease in serum HDL cholesterol in rats fed SF. HDL controls the lipid metabolism by removing free cholesterol from the peripheral tissue cells etherifying it and transporting it in the neutral lipid back to the liver for catabolism[15].Serum LDL and TG concentration are significantly higher in the SF diet compared to the control. LDL increases the rate of triacylglycerol catabolism by mobilizing fats from the liver to adipose tissue. It carries $60 \%$ to $70 \%$ of total cholesterol in the serum[15]. The hypertriglyceridemia produced by SF could be caused by enhanced liver VLDL-triglyceride secretion into the circulation[18].Studies report that with unsaturated TG, up-regulating of LDL receptor occurred compared to saturated TG. This suggests that dietary fatty acids as it can induce changes in cellular membrane lipids that may influence certain metabolic properties, such as receptor-mediated uptake of lipoproteins [19].It can also act like a hormone to control the activity or abundance of key transcription factors (metabolic regulators), and increase (HMG-CoA) reductase activity in the liver which is accompanied by raised cholesterogenesis rate and a down-regulation in LDL receptors[20]. It has been reported that lecithin-cholesterol-acyltransferase LCAT activity - the enzyme involved in the transesterification of cholesterol, maturation of HDL and flux of cholesterol from cell membranes into HDL tends to decrease in diet-induced situations of hypercholesterolemia. Moreover, the occurrence of an abnormal apoprotein (apo A-I) in HDL could also explain some changes in the LCAT activity [21].Concerning glucose homeostasis, there was a significant rise in blood glucose and insulin levels by $20.5 \%$ and $26.25 \%$ respectively, matching Axen et al, who found that consumption of high fat diet produced higher basal insulin release by the isolated islets that was attributed to insulin resistance in normal rats fed a high-fat diet [22,23] . However, Chen et al, found that rats fed a high-saturated fat diet displayed hyperinsulinemia without an elevation in the fasting plasma glucose level [23, 24].

These discrepancies may be explained by variations in the composition of the diet and in the balance between the effects of lipids on insulin sensitivity and on insulin secretion. Studies explained elevated blood glucose and insulin levels in animals consuming high-fat diet assuming that chronic exposure to elevated levels of FAs induces an increase in FA oxidation and a decrease in glucose oxidation. This suggest that a glucose-FA cycle may be operative in the $\beta$ - cell, assuming a defect in mitochondrial uncoupling proteins (UCPs) which uncouple mitochondrial respiration from oxidative phosphorylation, resulting in decrease ATP production[24,25].Saturated FA has proinflammatory actions, activates NF -B in monocytes and hepatocytes, which play an important role in the pathogenesis of local and systemic insulin resistance[26].Studies reported that ingestion of high SF induced increase in hepatic liposynthetic gene expression and impairment in glucose metabolism through: 1) impaired translocation of glucose transporter-4 activity, 2) suppressed expression of glucose transporter-4, 3) inhibited expression of hepatic glycolytic and lipogenic enzymes, and 4) impaired insulin signaling $[27,28]$.

\subsection{Effect of diet rich in saturated fat on lipolytic activity of adipose tissue:}

In the presence of adrenaline, the lipolytic activity of obese rats showed a significant decline in SC adipose tissue by $15 \%$ and a significant rise in visceral adipose tissue by $18 \%$, with a higher response in visceral adipose tissue compared to SC. In the presence of insulin there was a significant decrease in antilipolytic in both SC and visceral adipose tissue, by $30.33 \% \%$ and $25.84 \%$ respectively, with SC adipose tissue being more compliant to the antilipolytic effect of insulin. Regional differences in catecholamine-induced lipolysis and sensitivity to the antilipolytic effects of insulin have been extensively described in in vitro studies. Visceral adipocytes are more sensitive to catecholamine-induced lipolysis than subcutaneous adipose cells, being equally (or slightly less) sensitive to both $\alpha_{2}$-and adenosine receptor-dependent inhibition of lipolysis, and less sensitive

to insulin's antilipolytic effect [5]. There is increased sensitivity to catecholamine-induced lipolysis in visceral fat in non-obese individuals due to increase in the amount of $\beta_{1}$ and $\beta_{2}$-receptors, with normal receptor affinity and normal lipolytic action of agonists acting at post-adrenoreceptor steps in the lipolytic cascade; this is associated with enhanced $\beta_{3}$-adrenoreceptor sensitivity, which reflects changes in receptor number in comparison with subcutaneous adipocytes [29] .The site-related differences in lipolytic activity of fat cells may be due to differences in cyclic AMP production and $\beta$-adrenoceptor number, as catecholamines increase cyclic AMP production by stimulating $\beta$-adrenoceptors which leads to a sequence of events including elevation of adenylyl cyclase, activation of A-kinase and phosphorylation of hormone sensitive lipase HSL, ultimately 
resulting in an increase in lipolysis of fat cells as visceral fat cells contained a higher HSL activity than the subcutaneous cells[30]. Rat SC fat cells had lower HSL expressions compared to visceral fat cells [31].The of results of this study matched other studies that showed that diet can alter the ability of fat cells to transmit signals and that feeding SFAs results in lower activities in two major enzymes of the Lipolytic cascade: adenylate cyclase and HSL in SC, as SFAs decrease maximum lipolytic response to catecholamines in SC adipocytes with no change in ligand binding to B-receptor or in maximum basal adenylate cyclase activity $[5,32,33]$.It was found that visceral adipocytes of animals fed SFAs release more glycerol than those of fed control diet due to increased $\mathrm{B}_{3}$-adrenoceptor function, and decreased $\alpha_{2}$-adrenoceptor function [34].The results of this study run parallel with several epidemiologic and clinical studies that describe an association between high-fat diets and worsening of insulin sensitivity and consequently its antilipolytic activity in fat cells. As some of the adipokines participate in the regulation of lipolysis in adipose tissue, especially TNF- $\alpha$ and IL-6 enhancing triglyceride hydrolysis, their plasma levels are positively associated with insulin resistance [35]. In addition, as visceral adiposity develops in SF fed rats, visceral adipocytes enlarge. Large adipocytes are more insulin resistant than smaller adipocytes and therefore less sensitive to insulin effects that suppress lipolysis and promote reesterification of fatty acids [36, 37].

\section{Conclusion}

Consumption of diet rich in saturated fat in male rats showed a significant rise in BW which is associated with hypertension, dyslipidemia, hyperglycemia and insulin resistance. The adipose tissue of obese male rats showed a significant decrease in lipolytic activity of SC with a significant rise in the corresponding values in visceral adipose tissue.

\section{References}

[1] Fickova M, Hubert P, Wierzbicki A, et al. Dietary (n-3) and (n-6) polyunsaturated fatty acids rapidly modify fatty acid composition and insulin effects in rat adipocytes. J. Nutr 1998;128:512-519.

[2] Gavino G, Gavino VC. Modulation of polyunsaturated fatty acid content of triglycerides in rat preadipocytes in culture. Lipid 1991;26:705-710.

[3] Gaiva MHG, Couto RC, Oyama LM, et al. Polyunsaturated fatty acid-rich diets: effect on adipose tissue metabolism in rats. British Journal of Nutrition 2001;86:371-377.

[4] Spiegelman BM, Flier JS. Obesity and the regulation of energy balance Cell 2001; 104(4):531-43.

[5] Wajchenberg BL. Subcutaneous and visceral adipose tissue: their relation to the metabolic syndrome. Endocrine. Reviews 2000;21(6):697-738.

[6] Basciano H, Federico L, Adeli K. Fructose, insulin resistance, and metabolic dyslipidemia. Nutr Metab 2005;2(1):5

[7] Chi-Sun W, Nobuhiro F, Joseph AO. Studies on the mechanism of hypertriglyceridemia in the genetically obese Zucker rat. Journal of Lipid Research 1984;25:571-759.

[8] Rodbell M. Metabolism of isolated fat cells. The journal of chemistry 1964;230(2):375-380.

[9] Rodbell M, Birnbaumer L, Stephen L, et al. The Glucagon-sensitive Adenyl Cyclase System in Plasma Membranes of Rat Liver The journal of biological chemistry 1971;246( 6):1877-1882.

[10] Henry RJ. Clinical Chemistry - Principles and Techniques.Harper and Row 1974:664-666.

[11] Burits A, Young DS, Natio HK. Tietz Textbook of Clinical Chemistry 3rd ed. AACC 1999.

[12] Alsaifa M, Mansour S and Duwaihyb B. Influence of dietary fat quantity and composition on glucose tolerance and insulin sensitivity in rats. Metabolism 2004; 24(6):417-425.

[13] Duplus E, Glorian M and Claude F. Fatty Acid Regulation of Gene Transcription. The journal of biological chemistry 2000;275(40):30749-30752.

[14] Valensi P. Hypertension, single sugars and fatty acids; Journal of Human Hypertension 2005;19:S5-S9.

[15] Nworgu ZAM, Onwukaeme DN, Afolayan AJ, et al. Preliminary studies of blood pressure lowering effect of Nauclea latifolia in rats .African Journal of Pharmacy and Pharmacology 2008;2(2):037-041.

[16] Ajayi O, Bolanle A, David D. Effect of Oilseed Diets on Plasma Lipid Profile in Albino Rats. Pakistan Journal of Nutrition 2009;8(2):116-118.

[17] Dixon WW, Kenneth DM, Glenn KW, et al. High-Fat Diet Elevates Blood Pressure and Cerebrovascular Muscle Ca2+ Current. Hypertension 2000;35:832.

[18] Contreras RJ, Williams VL. Dietary obesity and weight cycling: effects on blood pressure and heart rate in rats. Am J Physiol Regul Integr Comp Physiol 1989;256:R1209-R1219.

[19] Oliveros LB, Videla AM, Giménez MS. Effect of dietary fat saturation on lipid metabolism, arachidonic acid turnover and peritoneal macrophage oxidative stress in mice. Braz J Med Biol Res 2004;37(3):311-320.

[20] Glatz JFC, Luiken JJFP, Bonen A. Membrane Fatty Acid Transporters as Regulators of Lipid Metabolism: Implications for Metabolic Disease. Physiol Rev 2010;90(1):367-417.

[21] Carmen MGP, Eduardo GP and Marina MC. Modification of Phospholipids Fatty Acid Composition in Reuber H35 Hepatoma Cells: Effect on HMG-CoA Reductase Activity. Journal of Cellular Biochemistry 2003;90:586-591.

[22] Angeles MZ, Barber A, Garcin H, et al. FACN Alterations in Carbohydrate and Lipid Metabolism Induced by a Diet Rich in Coconut Oil and Cholesterol in a Rat Model. Journal of the American College of Nutrition 1999;18(1):36-42.

[23] Axen KV, Dikeakos A, Sclafani A. High Dietary Fat Promotes Syndrome X in Nonobese Rats. J. Nutr 2003;133:2244-2249.

[24] Chen NG \& Reaven GM. Fatty acid inhibition of glucose-stimulated insulin secretion is enhanced in pancreatic islets from insulinresistant rats. Metabolism 1999; 48:1314-1317

[25] Popov D, Simionescu M and Shepherd PR. Saturated-fat diet induces moderate diabetes and severe glomerulosclerosis in hamsters.Diabetologia10.1007/s00125-003-1185-6 Springer-Verlag 2003. 
[26] Briaud I, Kelpe CL, Johnson LM, et al. Differential effects of hyperlipidemia on insulin secretion in islets of Langerhans from hyperglycemic versus normoglycemic rats. Diabetes 2002;51:662-668.

[27] Busetto, L. Visceral obesity and the metabolic syndrome: Effect of weight loss. Nutr. Metab. Cardiovasc. Dis 2001;11:195-204.

[28] Buettner R, Parhofer KG, Woenckhaus M, et al. Defining high-fat-diet rat models: metabolic and molecular effects of different fat types J Mol Endocrinol 2006;36:485-501.

[29] Segall L, Lameloise N, Assimacopoulos-Jeannet F, et al. Lipid rather than glucose metabolism is implicated in altered insulin secretion caused by oleate in INS-1 cells. Am J Physiol 1999;277:E521-E528.

[30] Giorgino F, Laviola L, Erikss JW. Regional differences of insulin action in adipose tissue: insights from in vivo and in vitro studies. Acta Physiologica Scandinavica 2005;183(1):13-30.

[31] Johan WEJ and Ellen EB. Catecholamine-induced lipolysis in adipose tissue and skeletal muscle in obesity. Physiology \& Behavior 2008;94(2):219-230.

[32] Valérie L, Arner P, Reynisdottir S, et al. Hormone-sensitive lipase expression and activity in relation to lipolysis in human fat cells Journal of Lipid Research 1998;39:1688- 1695.

[33] Soriguer F, Moreno F, Rojo-Martinez G, et al. Monounsaturated n-9 fatty acids and adipocyte lipolysis in rats Br J Nutr 2003;90:1015-22.

[34] Richard G. Vernon Effects of diet on lipolysis and its regulation Proceedings of the Nutrition Society 1992;51:397-408.

[35] Victor MR, Catalina P, Marı'a PP, et al. Dietary fat source regulates ob gene expression in white adipose tissue of rats under hyperphagic feeding. British Journal of Nutrition 2002;87:427-434.

[36] Björntorp P. "Portal" adipose tissue as a generator of risk factors for cardiovascular disease and diabetes. Arteriosclerosis July-Aug 1990;10(4):493-6.

[37] Miller RS, Becker KG, Prabhu V, et al. Cooke Adipocyte Gene Expression Is Altered in Formerly Obese Mice and As a Function of Diet Composition. J Nutr June 2008;138(6): 1033-1038. 